\title{
O LABIRINTO TEXTUAL DE O ANO DA MORTE DE RICARDO REIS,
}

\section{DE JOSÉ SARAMAGO}

\author{
Juliana Prestes de Oliveira ${ }^{1}$ \\ Raquel Trentin de Oliveira ${ }^{2}$
}

\begin{abstract}
RESUMO: No romance O ano da morte de Ricardo Reis (1984), do escritor José Saramago, que pode ser lido sob o viés do Pós-Modernismo, o autor constrói uma narrativa repleta de intertextos, em que a história das personagens dialoga com a história de Portugal em 1936, época na qual o país sofria a ditadura de Salazar. Buscamos explorar essa construção, investigando como ocorre a elaboração da narrativa e sua constituição histórico-literária. Ademais, refletimos sobre os limites entre ficção e(H)história, investigando como o romance contribui para a desestabilização dos discursos tidos como verdadeiros. Uma das estratégias do autor para problematizar a questão da veracidade da visão historiográfica tradicional é a utilização de diversas vozes, especialmente daquelas silenciadas pelo poder, o que sugere que um mesmo acontecimento pode ter várias versões. Refletindo crítica e reflexivamente sobre o passado, a ficção reconfigura a imagem dos acontecimentos históricos, apresentando-nos outra face da (H)história do país.
\end{abstract}

PALAVRAS-CHAVE: O ano da morte de Ricardo Reis; História; Literatura; Pós-Modernismo.

\begin{abstract}
In the novel $O$ ano da morte de Ricardo Reis (1984 ), by José Saramago, which can be read through Postmodernism, the author constructs a narrative full of intertexts, where the story of the characters dialogue with the history of Portugal in 1936, a time of the Salazar's dictatorship. We explore this construction investigating how the development of the narrative and its historical-literary creation occurs. Moreover, we reflect on the limits between fiction and (H)history investigating how the novel contributes to the destabilization of the discourses considered true. One of the strategies of the author to discuss the question of the truth of traditional historiographical vision is to use different voices, especially those silenced by power, suggesting that the same event can have multiple versions. Reflecting critically the past, the fiction reconfigures the image of historical events, showing us the other face of the $(\mathrm{H})$ history.
\end{abstract}

KEYWORDS: O ano da morte de Ricardo Reis; History; Literature; Postmodernism.

\footnotetext{
${ }^{1}$ Mestranda em Estudos Literárias do Programa de Pós-Graduação em Letras da Universidade Federal de Santa Maria UFSM. E-mail: jprestesdeoliveira@gmail.com.

2 Professora Adjunto do Curso de Letras e do Programa de Pós-Graduação em Letras da Universidade Federal de Santa Maria. E-mail: raqtrentin@yahoo.com.br.
} 


\section{INTRODUÇÃO}

Neste artigo, apresentamos um breve estudo do romance $O$ ano da morte de Ricardo Reis (1984), do escritor português José Saramago, tentando perceber a maneira como utiliza estratégias linguísticas e narrativas para entrelaçar ficção, realidade e $(\mathrm{H})$ história. Para isso, analisamos o romance sob o viés do Pós-Modernismo, tentando entender também como essa nova estética se apresenta na literatura e quais são seus principais ideais.

José Saramago inclui, nesse seu romance, diversos intertextos, a fim de estimular a questionar os discursos, principalmente aqueles tidos como verdade incontestável. Isso parece colocá-lo em conexão com o projeto do Pós-Modernismo, identificado, por Linda Hutcheon, como "[...] o desafio da certeza, a formulação de perguntas, a revelação da criação ficcional onde antes poderíamos ter aceitado a existência de alguma 'verdade' absoluta" (1991, p. 73, grifo da autora), há, assim, a relativização da história, no que concerne à interpretação dos fatos.

O romance põe em tensão personagens situadas no centro do poder e personagens socialmente marginalizadas, e por meio disso, temos acesso as diversas opiniões e visões referentes aos mesmos fatos. Tal tensão contribui para denunciar comportamentos e atitudes tomadas pelos poderosos para se manterem no centro e silenciar os que fossem contra eles. Desse modo, ocorre a revisitação ao passado não com a intenção de negar ou destruir o discurso histórico, mas, isto sim, de rever aquilo que é tido como verdade absoluta.

\section{LABIRINTO TEXTUAL DE SARAMAGO}

O ano da morte de Ricardo Reis foi publicado em 1984 e relata a história do último ano de vida de Ricardo Reis (um dos heterônimos do poeta português Fernando Pessoa), após sua volta a Portugal depois da notícia de que Fernando Pessoa havia falecido. O escritor Pessoa morreu sem ter escrito a morte de seu heterônimo Reis, Saramago aproveitou esse mote para continuar a história do heterônimo a partir do retorno de Reis, que estava no Brasil, a sua terra natal. Por meio desse enredo, descobrimos uma parte da história de Portugal, que estava passando pela ditadura de Salazar em 1936.

O personagem Ricardo Reis está desatualizado acerca dos assuntos de sua pátria, então, inicia um processo de readaptação. Para isso, conta com a ajuda do fantasma de Fernando Pessoa, que frequentemente o visita, informando-o da situação do país.

Como podemos perceber, nesse romance, o autor cria um jogo ficcional entre literatura e história, explorando a estreita relação existente entre esses dois campos. Como afirma Heloisa C. Milton (2012, p. 9), tal entrelaçamento permite um enriquecimento, tanto no discurso histórico quanto no ficcional:

Sem lugar a dúvidas, a disciplina histórica é filão inesgotável para a invenção poética, instituindo-se como uma plataforma de signos sobre a qual a narrativa literária engendra seus vastos mundos. Por outro lado, é indiscutível que as criações ficcionais também servem como testemunhos de épocas para interpretação 
histórica e que, entre os dois universos, cada qual orientado por suas próprias leis, impõem-se canais de negociação que se abrem ao estabelecimento de múltiplos sentidos.

Tal como o ficcional, o discurso historiográfico é um construto humano e linguístico. O reconhecimento dessa natureza acaba por nos fazer refletir sobre a constituição do passado histórico e as versões historiográficas escritas sobre ele. Consciente disso, o Pós-Modernismo reinsere "[...] os contextos históricos como sendo significantes, e até determinantes, mas, ao fazê-lo, problematiza toda a noção de conhecimento histórico" (HUTCHEON, 1991, p. 122). Conforme esclarece Linda Hutcheon:

Não se fez com que a história ficasse obsoleta; no entanto, ela está sendo repensada - como uma criação humana. E, ao afirmar, que a história não existe a não ser como texto, o pós-modernismo não nega estúpida e "euforicamente", que o passado existiu, mas apenas afirma que agora, para nós, seu acesso está totalmente condicionado pela textualidade. Não podemos conhecer o passado, a não ser por meio de seus textos: seus documentos, suas evidências, até seus relatos de testemunhas oculares são textos (HUTCHEON, 1991, p. 34, grifos da autora).

Fica claro, portanto, que a ideia não é negar "[...] a existência do passado", mas sim questioná-lo: pois “jamais poderemos conhecer o passado a não ser por meio de seus restos textualizados" (HUTCHEON, 1991, p. 39, grifos da autora).

Para problematizar a relação entre história e ficção e até mesmo a condição da literatura, os autores pós-modernos utilizam-se da metaficção historiográfica, conforme denominação de Linda Hutcheon (1991). Segundo a autora, metaficções historiográficas corresponderiam àquelas obras que são intensamente auto-reflexivas e mesmo assim, de maneira paradoxal, também se apropriam de acontecimentos e personagens históricos (HUTCHEON, 1991, p. 21). São “[...] obras de ficção que refletem sobre sua própria condição de ficção, destacando principalmente a figura do autor e o modo de escrever" (RAMOS, 1995, p. 16). Há nelas uma preocupação com a construção da linguagem em si e com o questionae mento acerca dos discursos representados, assim exercendo "importante papel no gesto de decifrar/interpretar o organismo social do passado" (MILTON, 2012, p. 10). A metaficção historiográfica então: “[...] demonstra que a ficção é historicamente condicionada e a história é discursivamente estruturada e [...] consegue ampliar o debate sobre as implicações ideológicas [...] entre poder e conhecimento - para os leitores e para a própria história [...]" (HUTCHEON, 1991, p. 158).

Saramago utiliza-se desse mecanismo em $O$ ano da morte de Ricardo Reis quando cria o envolvimento de personagens históricos e fictícios, permitindo a ampliação de nossa leitura e da compreensão do momento histórico de Portugal. Isso fica mais evidente quando ele traz Fernando Pessoa, personagem histórico, como um fictício fantasma, e Ricardo Reis, personagem fictício da lírica pessoana como pessoa de carne e osso do romance.

No decorrer do enredo, vamos descobrindo como está a situação de Portugal e de outros países, como quando o gerente do hotel comenta sobre a Espanha: "[...] três famílias 
espanholas [...] vêm fugidas [...] por causa de terem os comunistas ganho as eleições, Não fora os comunistas, foram as esquerdas, [...] Até os jornais falam disso" (SARAMAGO, 2001, p. 156). Ademais, há trechos em que Reis e Pessoa discutem sobre a situação da literatura, os efeitos que regimes ditatoriais podem causar nos textos literários e como esses podem ser utilizados como ferramenta de denúncia “[...] aqueles intelectuais que se sentem encarcerados nos regimes de força, mesmo quando essa força é mental, como a que dimana Salazar, esquecem-se de que a produção intelectual se intensificou nos regimes de ordem [...]" (SARAMAGO, 2001, p. 333).

Esse entrecruzamento estimula questionar os limites existentes entre o real e o imaginário, o que realmente aconteceu e o que foi inventado. Como Hutcheon (HUTCHEON, 1991, p. 64) afirma, "[...] a ficção é apresentada como mais um entre os discursos pelos quais elaboramos nossas versões da realidade, e tanto a elaboração como sua necessidade são o que se enfatiza no romance pós-modernista”. Assim, se a ficção é um dos discursos que utilizamos para retratar a nossa versão da realidade, os discursos históricos oficiais também não o seriam? É exatamente isso que os autores pós-modernos acabam por destacar por meio de suas obras, isto é, que mesmo os documentos (que se dizem não ficcionais) não conseguem ter a objetividade e neutralidade que conclamam.

Destarte, entendemos que tanto a ficção como a história podem ser manipuladas de acordo com algum objetivo ou intencionalidade de seu enunciador, o que contribui para a reflexão sobre qual dos discursos é mais verdadeiro, com a intenção de instalar uma desconfiança a respeito dos discursos (tanto histórico, como fictício), como pode ser observado no momento em que Reis lê jornais com informações acerca do falecimento de Fernando Pessoa:

[...] foi ontem a enterrar, surpreendeu-o a morte num leito cristão do Hospital de S. Luís, no sábado à noite, na poesia não era só ele, Fernando Pessoa, ele era também Álvaro de Campos, e Alberto Caeiro, e Ricardo Reis, pronto, já cá faltava o erro, a desatenção, o escrever por ouvir dizer, quando muito sabemos, nós, que Ricardo Reis é sim este homem que está lendo o jornal com os seus próprios olhos abertos e vivos, médico, de quarenta e oito anos de idade, mais um que a idade de Fernando Pessoa quando lhe fecharam os olhos, esses sim, mortos, não deviam ser necessárias outras provas ou certificados que não se trata da mesma pessoa, e se ainda aí houver quem duvide, esse vá ao Hotel Bragança e fale com o senhor Salvador, que é o gerente (SARAMAGO, 2001, p. 36).

A partir desse fragmento, percebemos que o discurso ficcional constrói o personagem Ricardo Reis como indivíduo independente de seu criador, Fernando Pessoa, capaz de viver para além dele. Novamente, não é somente uma tentativa, por parte de Saramago, de enganar o leitor, mas sim de subverter as condições do real e do ficcional. Para ele, assim como para outros escritores pós-modernos, “[...] fazer ficção implica exercitar à exaustão o sentido do possível. Para isso, congregam-se os discursos que tangem a realidade cotejando-os com os mecanismos da (i)lógica ficcional, buscando-se os limites da própria linguagem" (FIORUCI, 2012, p. 146). 
Esse embaralhar dos limites entre o real e o ficcional também pode ser observado no que diz respeito à própria relação existente entre Fernando Pessoa, personagem histórico e por isso considerado real (que, no entanto, surge como fantasma) e Ricardo Reis, seu heterônimo e por isso sujeito ficcional (que, entretanto, aparece como personagem real). Durante todo o enredo, há encontros de Reis e Pessoa nos quais se perde as fronteiras que definem quem é quem. Como, por exemplo, a primeira vez em que Ricardo encontra Pessoa:

Então como tem passado, um deles fez a pergunta, ou ambos, não importa averiguar [...] Ricardo Reis despiu a gabardina, pousou o chapéu, arrumou cuidadosamente o guarda-chuva no lavatório [...] Puxou uma cadeira e sentou-se defronte o visitante, reparou que Fernando Pessoa [...] não veste sobretudo nem gabardina nem qualquer outra proteção contra o mau tempo [...] Ricardo Reis tirou a carteira do bolso interior do casaco, extraiu dela um papel dobrado, fez menção de o entregar a Fernando Pessoa, mas este recusou com um gesto, disse, Já não sei ler, leia você, e Ricardo Reis leu, Fernando Pessoa faleceu Stop Parto para Glasglow Stop Álvaro de Campos (SARAMAGO, 2001, p. 80).

Vê-se como Ricardo Reis é constituído como sujeito através de menções que indicariam a sua humanidade - como o fato de usar a gabardina, o chapéu e o guarda-chuva - enquanto Pessoa não usa qualquer vestimenta que o proteja do tempo. Também, Fernando Pessoa conta a Reis que já não consegue mais ler, enquanto Reis, por ainda estar vivo, o faz. Desse modo, cria-se a condição de morto de Pessoa e de sujeito "real" de Reis. Ainda é válido destacar que outro dos heterônimos de Fernando Pessoa - no caso Álvaro de Campos como sendo também representado como sujeito real, e não somente um personagem criado pelo poeta.

Por meio desse romance de Saramago, percebemos que a literatura pós-moderna vem mostrar que "[...] as fronteiras mais radicais que já se ultrapassaram foram aquelas existentes entre a ficção e a não-ficção [...] entre a arte e a vida” (HUTCHEON, 1991, p. 27). Mas, então, se o Pós-Modernismo reconhece a “[...] pobreza da palavra escrita enquanto processo de comunicação" (SANTIAGO, 2002, p. 56) e a incapacidade da arte em geral de representar a vida: por que insere personagens e fatos históricos em meio à ficção? Na verdade essa ficção:

[...] não reflete a realidade, nem a reproduz. Não pode fazê-lo. Na metaficção historiográfica não há nenhuma pretensão de mimese simplista. Em vez disso, a ficção é apresentada como mais um entre os discursos pelos quais elaboramos nossas versões da realidade, e tanto a elaboração como sua necessidade são o que se enfatiza no romance pós-modernista (HUTCHEON, 1991, p. 64).

Pensando nesses limites da linguagem e nos existentes entre real e ficcional, além do fato de que é através dos discursos que elaboramos as nossas versões dos fatos e que esses discursos carregarem a subjetividade e a intencionalidade de quem os profere, vemos outra estratégia utilizada por Saramago para desafiar a versão oficial. O enredo do romance 
apresenta inúmeras vozes e, assim, revela outras versões do mesmo acontecimento, que estão ligadas com as intenções dos falantes, permitindo que tenhamos acesso a uma visão diferente dos fatos e possamos escolher no que acreditar. Vemos isso nesse trecho onde os personagens discutem sobre os discursos que são publicados nos jornais: “[...] voltando ao Salazar, quem diz muito bem dele é a imprensa estrangeira, Ora, são artigos encomendados pela propaganda, pagos com o dinheiro do contribuinte, lembro-me de ouvir dizer, Mas olhe que imprensa de cá também se derrete em louvações" (SARAMAGO, 2001, p. 278-279).

O mesmo se observa na reportagem lida por Reis sobre o que acontecia em Portugal e nos países vizinhos, como no excerto: “[...] escrevem-se nos jornais [...] sobre a derrocada dos grandes Estados, o português, o nosso, afirmará a sua extraordinária força e a inteligência reflectida dos homens que a dirigem." (SARAMAGO, 2001, p. 85). Juntamente com essas vozes trazidas pelos jornais, há da personagem Lídia, a humilde camareira do hotel, com quem Ricardo Reis tem um caso amoroso, ela lhe narrava o que estava acontecendo no país. Percebemos que ela tinha acesso a outras opiniões, a partir das quais formava a sua: "[...] o meu irmão diz é que não se deve fazer sempre fé no que os jornais escrevem [...]." (SARAMAGO, 2001, p. 388), ademais, no decorrer do livro, observamos que várias vezes Lídia é mais crítica e decidida do que Reis, ela reconhece que os jornais são manipulados de acordo com os ideais convenientes a quem os escreve, publica ou os mantêm. Há mesmo um momento em que ela contraria as ideias de Reis com relação aos textos jornalísticos:

Li no jornal, e também li, escrito por um senhor jornalista chamado Tomé Vieira, autor de livros, que os bolchevistas arrancaram os olhos a um padre já velho e depois regaram-no com gasolina e deitaram-lhe o fogo, Não acredito, Está no jornal, eu li, Não é do senhor doutor que eu duvido, o que meu irmão diz é que não se deve fazer sempre fé no que os jornais escrevem (SARAMAGO, 2001, p. 388).

Por meio do uso de várias vozes, principalmente daquelas oprimidas pelos detentores de poder, a literatura pós-moderna (você não tem como afirmar o que os autores pós-modernistas em geral procuram, uma parte nem se declara pós-modernista, você tem como avaliar o que o texto literário conseguiu alcançar) reavalia o passado, busca "pôr a nu o não-dito por trás do que foi dito", "o silenciado (reprimido) sob o que foi falado" (SANTOS, 2001, p. 71). No mesmo sentido, Umberto Eco (1985, p. 56-57), declara que a resposta pósmoderna "[...] consiste em reconhecer que o passado, já que não pode ser destruído porque sua destruição leva ao silêncio, deve ser revisitado: com ironia, de maneira não inocente". É o que faz Saramago ao explorar o relato daqueles que não eram ouvidos, colocando frente a frente o ponto de vista do opressor e do oprimido, pois, "todos os grupos têm o direito de falar por si mesmo, com sua própria voz, e de terem aceita essa voz como autêntica e legítima” (HARVEY, 2001, p. 52).

No romance, tais vozes também surgem pela atuação do narrador que, aos poucos, conta o que acontece no país em 1937: “[...] a direita tinha ganho em dezassete províncias, mas, contados os votos todos, viu-se que a esquerda elegera mais deputados [...]. Começaram a correr boatos de estar em preparação um golpe militar [...].” (SARAMAGO, 2001, p. 153). Ele também nos revela como a ditadura de Salazar foi se instaurando, e desse modo 
conhecemos um pouco mais, por uma perspectiva irônica, a história de Portugal: “[...] o aparecimento do professor António de Oliveira Salazar, há oito anos, [...] para salvar o seu país e o nosso país do abismo, para restaurar, para lhe impor uma nova doutrina [...]." (SARAMAGO, 2001 p. 298).

Além do narrador, temos a visão do personagem Fernando Pessoa que relata o que aconteceu no país no período que Reis estava fora, a fim de ajudá-lo a entender o que está acontecendo: "Lembro-me de ler, nos meus últimos dias, umas notícias sobre essa revolução, foi uma coisa de bolchevistas, creio. [...] Aqui em Portugal também tem havido umas revoluções [...]" (SARAMAGO, 2001, p. 81). Por meio das falas de Pessoa, podemos construir a imagem que muitos tinham de Salazar e como essa imagem era construída pela imprensa da época: "É o ditador português, o proctetor, o pai, o professor, o poder manso, um quarto de sacristão, um quarto de sibila, um quarto de Sebastião, um quarto de Sidónio [...] Ora são artigos encomendados pela propaganda, pagos com dinheiro do contribuinte [...]." (SARAMAGO, 2001, p. 278-279).

Ricardo Reis, por sua vez, também ajuda a traçar um panorama da situação em Portugal, como quando reflete sobre o que lê, ouve ou vê: "Este país está um desmazelo, os barcos que vão para a água antes do tempo, os presos que se somem, os carteiros que não entregam as cartas, os varredores, enfim, dos varredores não há nada a dizer." (SARAMAGO, 2001, p. 342). É por meio dele que vemos como o regime agia com os recém chegados no país, que poderiam apresentar algum tipo de ameaça, como quando ele é levado a depor pelo simples fato de ter morado no Brasil e poder ter tido contato com pessoas influentes: "[...] A polícia deve ter pouco o que fazer, para assim perder tempo com quem não tem culpas e nem se prepara para tê-las [...]" (SARAMAGO, 2001, p. 331). Reis também nos leva a refletir sobre o que os jornais apresentam como verdade: “[...] tenho que acreditar que é verdade o que eles me dizem, um jornal não pode mentir, seria o maior pecado do mundo [...]" (SARAMAGO, 2001, p. 388).

A partir disso, a narrativa estabelece uma posição questionadora, estimulando o leitor a sair de seu lugar-comum para repensar criticamente a história, a sociedade, o discurso oficial, e todos os outros a que é diariamente exposto, bem como a maneira com que os países eram e são governados. Nessa perspectiva, percebemos a importância desse romance de Saramago para compreendermos umas das fases vividas por Portugal.

\section{CONSIDERAÇÕES FINAIS}

Com base na análise, podemos perceber que $O$ ano da morte de Ricardo Reis enquadrase nos moldes principais da metaficção historiográfica, especialmente por dialogar criticamente com a $(\mathrm{H})$ história, explorando inúmeras vozes, inclusive do excêntrico e marginalizado. Uma das intenções do Pós-Modernismo é demonstrar que os discursos são carregados de intenções e subjetividades, explicitar o modo de manipulação discursiva dos que estão no poder. Não se quer, no entanto, destruir ou negar a História, o que se pretende é revisitar o passado, analisar cuidadosamente tudo que aconteceu, mas de uma forma mais crítica. Com isso, o texto literário exige um leitor mais reflexivo e analítico, atento ao que está nas 
entrelinhas do discurso. Contribui, portanto, para formar sujeitos questionadores diante de informações dadas como verdadeiras e incontestáveis e, por consequência, para uma sociedade menos alienada e manipulável.

\section{REFERÊNCIAS}

ECO, Umberto. Pós-escrito a O Nome da rosa. Tradução: Letizia Zini Antunes e Álvaro Lorencini. Rio de Janeiro: Nova Fronteira, 1985. 66 p.

FIORUCI, Wellington Ricardo. O labirinto da escritura: ficção e memória nas poéticas de Ricardo Piglia e Umberto Eco. In: FIORUCI, Wellington Ricardo; FIORUCCI, Rodolfo. (Org.). Vestígios de memória: diálogos entre literatura e história. Curitiba, PR: CRV, 2012. p. 145-160.

HARVEY, David. Condição pós-moderna: Uma Pesquisa sobre as Origens da Mudança Cultural. Tradução: Adail Ubirajara Sobral e Maria Stela Gonçalves. 21. ed. São Paulo: Loyola, 348 .2011 p.

HUTCHEON, Linda. Poética do Pós-Modernismo: história - teoria - ficção. Tradução: Ricardo Cruz. Rio de Janeiro: Imago, 1991. 330 p.

MILTON, Heloisa Costa. Prefácio: A literatura lê a história, a história não deixa de ler a literatura. In: FIORUCI, Wellington Ricardo; FIORUCCI, Rodolfo. (Org.). Vestígios de memória: diálogos entre literatura e história. Curitiba: CRV, 2012, p. 9-14.

RAMOS, Tânia Regina Oliveira. Pode-se (não) falar de pós-modernidade? Revista Anuário de Literatura, Florianópolis, Santa Catarina: UFSC, n. 3, p. 13-20, 1995. Disponível em: <https:// periodicos.ufsc.br/index.php/literatura/article/view/5265>. Acesso em: 02 ago. 2012.

SANTIAGO, Silviano. O narrador pós-moderno. In: . Nas malhas da letra. Rio de Janeiro:

Rocco, 2002, p. 44-60.

SANTOS, Jair Ferreira. O que é Pós-moderno. São Paulo: Brasiliense, 2004. 165 p.

SARAMAGO, José. O ano da morte de Ricardo Reis. 1. ed. 9. reimp. São Paulo: Companhia das Letras, 2001. $415 \mathrm{p}$. 